\title{
El reto de la internacionalización de la educación superior en ALC
}

\section{The challenge of the internationalization of higher education in LAC}

\author{
Roberto Escalante Semerena \\ Secretario General \\ Unión de Universidades de América Latina y el Caribe \\ semerena@unam.mx
}

Palabras clave: Internacionalización, movilidad, cooperación, calidad, pertinencia.

Una de las consecuencias naturales de la globalización económica ha sido que muchas otras áreas se hayan globalizado también. Con intensidades diferentes, derivadas de sus características particulares, hoy vivimosun mundo en el que prácticamente todas las actividades humanas se han vuelto verdaderamente globales. La educación superior no podía, ni debía, ser ajena a este proceso de globalización.

De acuerdo con José Joaquín Brunner, la competencia global constituye un reto para las IES de ALC, ya que éstas deberán enfrentarla no sólo en el nivel interno, sino un mundo donde la competencia de formación también está globalizada.

"La competencia ya no va a ser entre las instituciones universitarias de una región o de un país, sino que va a ser, cada vez más, una competencia global".

Las instituciones de educación superior de nuestras regiones han desarrollado diferentes aproximaciones parainsertarseenlaglobalización, pero con el surgimiento de la idea de crear un Espacio Europeo de Educación Superior (EEES), y luego con su impactante puesta en marcha, instituciones de Educación Superior (ES) de muchos países, lo mismo que sus gobiernos han reaccionado con enorme interés.

En algunos casos, estas instituciones han intentado incorporarse a ese proyecto, lo que hasta ahora está limitado al espacio europeo y sus vecinos; otra forma de incorporarse a este nuevo movimiento global ha sido planteando la creación de sus propios espacios regionales de integración educativa.

En nuestra región vienen discutiéndose, e intentando llevarse a la práctica, diferentes aproximaciones para construir espacios supranacionales de educación superior con especificaciones que derivan de la manera en la que se define la región misma. Una primera propuesta está determinada por la definición de un espacio específicamente latinoamericano, que bajo la idea de ENLACES plantea la creación de un "espacio" de diálogo que articule acciones para la reforma de los sistemas de educación superior; junto a ella, y relativamente próxima, está otra aproximación que tiene relevancia histórica, en la que se habla de un ámbito mayor que es el de Iberoamérica, que añade a dos integrantes de importancia: España y Portugal, que se ha denominado espacio Iberoamericano de Conocimiento; la tercera plantea la idea de construir un espacio continental, que reuniría a universidades de los países de América Latina y el Caribe con las de Norteamérica: Canadá y Estados Unidos.

Interesa destacar que, más que plantearnos divergencias, estos esfuerzos tienen una amplia posibilidad de convergencia, si es que se ponen de relieve los aspectos comunes que incorporan. Interesa destacar, de igual manera, que ninguna de estas aproximaciones ha alcanzado el grado de avance logrado en Europa que, por supuesto, tuvo un ingrediente particular: ser un espacio económico y geopolítico común. 
En realidad, comparativamente su grado de avance en relación con el EEES es muy limitado, restringido a pequeñas, pero importantes, experiencias, como la Iniciativa Iberoamericana de Movilidad de estudiantes y profesores Pablo Neruda, el Programa Académico de Movilidad Educativa que hemos venido realizando en la UDUAL o el Educativo-Mercosur.

Conviene, por ello, reflexionar sobre aquellos aspectos que han dificultado la plena operación de los espacios comunes de educación superior, ya sea en América continental, Iberoamérica o Latinoamérica.

La agenda de la internacionalización de la educación superior tiene un cimiento en la CRES 2008, celebrada en Cartagena de Indias, Colombia, en donde se definieron las siguientes acciones:

1. Renovar los sistemas educativos para mejorar la compatibilidad entre programas, instituciones, modalidades y sistemas de registro, integrando la diversidad institucional y cultural;

2. Crear un sistema regional de información de educación superior, que incluya un mapa universitario, como base para la movilidad académica y las políticas públicas;

3. Desarrollar un programa de convergencia de los sistemas de acreditación y evaluación nacionales y subregionales, que permita estandarizar procedimientos de aseguramiento de la calidad de programas docentes y de investigación, legitimados por su contribución social;

4. Reconocer estudios, diplomas y títulos a partir de un sistema de créditos académicos comunes;

5. Promover la movilidad intrarregional de estudiantes, investigadores, profesores y personal administrativo, contando con fondos específicos de apoyo;

6.Impulsar proyectosconjuntos deinvestigación y constituir redes regionales de investigación y docencia universitarias y pluridisciplinarias;

7. Establecer instrumentos comunes de comunicación que favorezcan la circulación de información, sistemas de aprendizaje y el conocimiento nuevo;
8. Impulsar programas de educación a distancia compartidos, apoyados en instituciones regionales que combinen educación virtual y presencial y

9. Fortalecer el aprendizaje de idiomas para favorecer los intercambios en toda la región.

Ello en la perspectiva de empezar a plantear un agenda detallada de acuerdos que debieran alcanzar las instancias estatales y universitarias correspondientes para poder llevar a cabo proyectos de esta envergadura. Agenda que debiera incorporar, en el primer punto, la definición de los requerimientos necesarios para queuniversidades puedan participar en la primera etapa del proceso de construcción de este espacio común; en segundo lugar, debiera atenderse la necesidad de establecer el compromiso formal de las Universidades que estén en condiciones de iniciar en el mediano plazo procesos de armonización de estudios, de mejoras en la pertinencia social de sus programas académicos y de desarrollo de la capacidad de movilizar un número significativo de estudiantes y profesores de los tres ciclos educativos: licenciatura, maestría y doctorado); en tercer lugar, debe impulsarse el acuerdo de las instancias gubernamentales para ayudar a que este proceso pueda llevarse adecuadamente, no solamente en términos de los recursos necesarios, sino sobre todo de su participación en la creación y funcionamiento de la(s) instancia(s) que tengan la responsabilidad de conducir el proceso.

El primer punto de la agenda que acabamos de señalar es el de las instituciones de educación superior que participarían en la primera etapa de construcción del Espacio de Educación Superior. El tema es relevante dada la complejidad del desarrollo de la educación superior latinoamericana. Si enfocamos esta evolución con una perspectiva de economía política, podemos advertir que en América Latina las instituciones de educación superior se diferencian por su tamaño, por sus tasas de participación, por sus relaciones con el Estado, por el peso relativo de la matrícula privada.

Al mismo tiempo observamos las siguientes características comunes: una proliferación de 
instituciones de educación terciaria de diverso tipo; una fuerte $\mathrm{y}$ creciente presencia privada, independientes del financiamiento estatal, que conforman la mayoría de la plataforma institucional latinoamericana; consecuentemente, una educación superior extremadamente diferenciada que, además, se diversifica continuamente; un predominio relativo de las principales universidades estatales en cada país; una alta concentración de la investigación académica en pocas universidades, la mayoría públicas aunque existen también privadas; finalmente, una tendencia al conflicto entre legitimidad y efectividad en el gobierno de las universidades.

Dadas estas diversidades, es claro que el propósito de armonizar los sistemas de créditos, la manera en la que se otorgan títulos y diplomas y la duración de programas académicos, tiene que definirse con mucho cuidado.

Esto nos lleva al segundo punto de la agenda propuesta: es evidente que esta armonización académica no puede implementarse simultáneamente en este abigarrado conjunto de instituciones. Conviene, de esta manera, discutir cuidadosamente las características de las universidades con las que pudiera iniciarse este proceso de armonización. Seleccionado el universo de referencia habría que plantear su formalización en una gran reunión con los rectores involucrados. Por supuesto se trata de una primera etapa a la que habrán de seguir varias más, definidas a partir de las reglas de incorporación de nuevas instituciones que vayan cumpliendo con los requisitos avaladas por las primeras entidades participantes.
El tercer punto es de fundamental importancia. Los gobiernos de la región tienen una incidencia muy relativa en el manejo de los asuntos universitarios, lo que ha sido central en el desarrollo de nuestras universidades. La autonomía universitaria ha permitido que las instituciones de educación superior sean entidades estatales, ajenas a los avatares electorales y a las personalidades de gobernantes y a las distintas correlaciones de fuerzas en los parlamentos. Ello, sin embargo, no elimina la obligación de esas entidades gubernamentales en relación con el financiamiento de la educación superior. Por ello, la participación de las autoridades educativas derivadas de los poderes electos es central para la creación de un espacio común de educación superior en la región.

No puede concluirse una reflexión propositiva, como esta sin advertir sobre la necesidad de diseñar un órgano que conduzca el proceso. En el caso europeo fue el Consejo de Ministros de Educación. En nuestro caso tiene que ser una conducción tripartita: los rectores de las universidades involucradas, los gobiernos de los países en los que se localizan esas universidades y redes cuya permanencia y trascendencia los habiliten para moderar las reuniones de trabajo y dar seguimiento a los acuerdos. Cabe destacar que deben ser las universidades quienes, con base en sus propios principios y autonomía, guíen el difícil trance hacia la consolidación de un espacio de integración regional basado en el conocimiento. 